\title{
Pathogenesis of Kupffer Cells in Cholestatic Liver Injury
}

\author{
Keisaku Sato, ${ }^{* \dagger \ddagger}$ Chad Hall, ${ }^{\dagger \S}$ Shannon Glaser, ${ }^{* \dagger+}$ Heather Francis, ${ }^{* \dagger \ddagger}$ Fanyin Meng, ${ }^{* \dagger+}$ and Gianfranco Alpini ${ }^{* \dagger \dagger}$
}

From Research,* Central Texas Veterans Health Care System, and the Department of Medicine, ${ }^{\dagger}$ Texas A\&M Health Science Center, College of Medicine, Temple; and the Scott \& White Digestive Disease Research Center, ${ }^{\ddagger}$ Scott \& White, and Academic Research Integration, ${ }^{\S}$ Department Surgery, Baylor Scott \& White Healthcare, Temple, Texas

\author{
Accepted for publication \\ June 7, 2016. \\ Address correspondence to \\ Gianfranco Alpini, Ph.D., Scott \\ and White Digestive Diseases \\ Research Center, Central Texas \\ Veterans Health Care System, \\ Texas A\&M Health Science \\ Center, College of Medicine, \\ Olin E. Teague Medical Center, \\ 1901 S 1st St, Bldg 205, 1R60, \\ Temple, TX 76504. E-mail: \\ galpini@medicine.tamhsc.edu.
}

\begin{abstract}
Kupffer cells are the resident macrophages in the liver. They are located in hepatic sinusoid, which allows them to remove foreign materials, pathogens, and apoptotic cells efficiently. Activated Kupffer cells secrete various mediators, including cytokines and chemokines, to initiate immune responses, inflammation, or recruitment of other liver cells. Bile duct ligation (BDL) surgery in rodents is often studied as an animal model of cholestatic liver disease, characterized by obstruction of bile flow. BDL mice show altered functional activities of Kupffer cells compared with sham-operated mice, including elevated cytokine secretion and impaired bacterial clearance. Various mediators produced by other liver cells can regulate Kupffer cell activation, which suggest that Kupffer cells orchestrate with other liver cells to relay inflammatory signals and to maintain liver homeostasis during BDL-induced liver injury. Blocking or depletion of Kupffer cells, an approach for the treatment of liver diseases, has shown controversial implications. Procedures in Kupffer cell research have limitations and may produce various results in Kupffer cell research. It is important, however, to reveal underlying mechanisms of activation and functions of Kupffer cells, followed by hepatic inflammation and fibrosis. This review summarizes present Kupffer cell studies in cholestatic liver injury. (Am J Pathol 2016, 186: 2238-2247; http:// dx.doi.org/10.1016/j.ajpath.2016.06.003)
\end{abstract}

Kupffer cells are tissue-resident macrophages in the liver. They have high phagocytic capability, allowing them to remove foreign materials, such as viruses and bacteria, as well as apoptotic cells and cellular debris. This is an important role of Kupffer cells as a gatekeeper in the innate immune response. ${ }^{1}$ Kupffer cells are located in the hepatic sinusoids and can migrate along hepatic sinusoidal endothelial cells, ${ }^{2}$ allowing them to remove foreign pathogens entering the liver from the portal venous system efficiently. They also function as active sensory cells that detect immunoreactive materials, such as lipopolysaccharide (LPS), which is a component of the outer membrane of Gram-negative bacteria and a strong trigger for immune responses. Activated Kupffer cells secrete several mediators that regulate inflammation and homeostasis, as well as drive the inflammatory response to liver injury. ${ }^{3}$ Therefore, several studies have attempted to reveal the role and function of Kupffer cells in liver pathology to seek therapeutic treatments for chronic cholestatic liver diseases. This review summarizes the current studies regarding the role of Kupffer cells in liver diseases, especially in cholestatic liver injury.

\section{Cholestatic Liver Injury}

Cholestatic liver diseases, including primary biliary cirrhosis and primary sclerosing cholangitis, occur in extrahepatic and/

Supported in part by the Dr. Nicholas C. Hightower Centennial Chair of Gastroenterology from Scott \& White, a VA Research Career Scientist Award, a VA Merit Award (5I01BX000574 to G.A.), US Department of Veterans Affairs Biomedical Laboratory Research VA Merit Awards (1I01BX001724 to F.M., 5I01BX002192 to S.G., and 1I01BX003031 to H.F.), NIH grants DK058411, DK076898, DK107310, and DK062975 (G.A., F.M., and S.G.), and NIH RO1 (1R01DK108959-01 to H.F.). This material is the result of work supported by resources at the Central Texas Veterans Health Care System.

The views expressed herein are those of the authors and do not necessarily represent the views of the Department of Veterans Affairs.

Disclosures: None declared. 
or intrahepatic bile ducts. Cholestatic liver diseases are characterized by the accumulation of specific bile acids in the liver that initiate an inflammatory process leading to liver injury. Patients with cholestatic liver diseases may present with pruritus, fatigue, jaundice, and dark urine. ${ }^{4}$ Although the detailed mechanisms are still not fully understood, it is known that bile salts are toxic and induce hepatocyte apoptosis in vitro. ${ }^{5}$ Bile acids also disrupt the integrity of the biliary epithelium by affecting cholangiocyte secretion, proliferation, and survival. ${ }^{6,7}$ A previous study has demonstrated that bile depletion attenuates cholangiocyte proliferation, ${ }^{8}$ and other studies have shown that bile acids, taurocholic acid, and taurolithocholic acid can induce ductal secretion and cholangiocyte proliferation as well as up-regulation of bile acid transporter in rats. ${ }^{9,10}$ Another study has also shown that taurocholic acid has protective effects against caffeic acid-induced cholangiocyte apoptosis by enhancing vascular endothelial growth factor production leading to cholangiocyte proliferation. ${ }^{11} \mathrm{~A}$ recent study has shown that bile acids inhibit LPS-induced proinflammatory cytokine secretion from macrophages, ${ }^{12}$ and it is also known that bile acids modulate innate and adaptive immunity, including inhibition of immunoglobulin production. ${ }^{13,14}$ These studies indicate that bile acid accumulation is associated with not only cholangiocyte proliferation but also altered immune responses via liver cells, including Kupffer cells, and this may be responsible for liver damage, inflammation, and fibrosis during cholestasis.

In cholestatic liver disease research, bile duct ligation (BDL) is commonly used for rodent models. BDL is a surgically induced extrahepatic biliary obstruction of the common bile duct that prevents bile flow and mimics cholestasis followed by cholestatic liver injury. Rodent models show altered phagocytic, immune, and macrophage functions after BDL. ${ }^{15,16}$ BDL can be performed for gene knockout mice to evaluate functions of the gene of interest during cholestasis. ${ }^{17}$ It is often observed that patients with cholestatic liver diseases have a higher incidence of perioperative infectious complications. Bacterial infection and inflammation is closely associated with cholestatic liver diseases ${ }^{18}$; bacterial infection can cause cholestasis, and cholestasis increases susceptibility to bacterial infection. Nakano et $\mathrm{al}^{19}$ have demonstrated that BDL rats become more susceptible to LPS compared with the control group. Although a previous study has shown that BDL rodents may not perfectly mimic disease conditions of human cholestatic liver injury ${ }^{20}$ as well as it requires technical surgery, BDL followed by LPS or bacteria injection can be a tool for studies of cholestasis and bacterial infection as well as inflammation.

\section{Heterogeneity of Kupffer Cells}

\section{M1 and M2 Macrophages}

Macrophages can be classified into two distinct subsets, M1 and M2. In response to various signals, Kupffer cells may undergo classic M1 activation or alternative M2 activation.
M1 Kupffer cells exhibit a proinflammatory phenotype and can be activated by pathogens or toxins, such as LPS, and release proinflammatory cytokines, including tumor necrosis factor (TNF)- $\alpha$, IL- 6 and IL-1 $\beta$, as well as transforming growth factor- $\beta$ that induces fibrogenesis by activation of hepatic stellate cells (HSCs) and reactive oxygen species (ROS), leading to inflammation and liver damage. ${ }^{21,22} \mathrm{IL}-6$ also induces cell proliferation in hepatocytes and cholangiocytes and could lead to carcinogenesis via activating phosphatidylinositol 3, Janus activating kinase/STAT, and p38 mitogen activated protein kinase pathways. ${ }^{23}$ ROS causes unfolded proteins to accumulate within the endoplasmic reticulum of hepatocytes, initiating hepatic steatosis, inflammation, and apoptosis because of endoplasmic reticulum stress. $^{24}$ M2 Kupffer cells display antiinflammatory phenotypes that can be activated by IL-4 and IL-13 releasing IL-4, IL-10, IL-13, and transforming growth factor- $\beta$ leading to wound repair and fibrosis. ${ }^{21,22}$ Table 1 summarizes mediators of Kupffer cells in liver injury, and Figure 1 shows functional differences between M1 and M2 Kupffer cells.

The balance of M1/M2 Kupffer cells may be a key in liver pathology. For example, a recent study has demonstrated that $\mathrm{BALB} / \mathrm{c}$ mice, which have dominant M2 macrophages, show attenuated hepatic steatosis and inflammation compared with C57BL/6 mice (M1 dominant) induced by methioninecholine-deficient diet. Another study using BALB/c and C57BL/6 mice has shown that M2 Kupffer cells induce M1 Kupffer cell apoptosis via IL-10 secretion and regulate M1/M2 balance, leading to protective effects against alcohol or high-fat diet-induced hepatic steatosis and apoptosis. ${ }^{36}$ These findings suggest that activation of M2 Kupffer cells and the regulation of M1/M2 balance could be a potential target of treatment for liver diseases.

\section{Liver-Resident and Bone Marrow-Derived Macrophages}

There are also two subsets of liver macrophages, depending on derivations: self-renewing liver-resident macrophages derived from embryonic progenitors (Kupffer cells) and bone marrow-derived macrophages circulating in blood stream as monocytes and recruited in the liver to differentiate into macrophages. ${ }^{44}$ A study has revealed that functional properties are different between these two subsets in acute liver injury induced by $N$-acetyl-p-aminophenol. ${ }^{45}$ Other studies, however, have shown that bone marrow-derived monocytes can be differentiated into self-renewing Kupffer cells as well as M1 and M2 subsets. ${ }^{46,47}$ During liver injury, it is known that bone marrow-derived monocytes are recruited in the liver to accelerate liver regeneration via communication with Kupffer cells. ${ }^{48,49}$ A recent study has shown that sphingosine 1-phosphate receptor 2 and 3 mediate bone marrow-derived monocyte recruitment in BDL mice. ${ }^{50}$ These earlier findings suggest that not only Kupffer cells but also bone marrow-derived macrophages may play key roles in liver repair 
Table 1 Mediators Associated with Kupffer Cells and Cholestatic Liver Injury

\begin{tabular}{|c|c|}
\hline Mediators & $\begin{array}{l}\text { Pathophysiological events } \\
\text { induced by mediators }\end{array}$ \\
\hline \multicolumn{2}{|c|}{ M1 Kupffer cells } \\
\hline TNF- $\alpha$ & Inflammation and apoptosis ${ }^{25}$ \\
\hline $\mathrm{IL}-1$ & $\begin{array}{c}\text { Inflammatory responses, }{ }^{26} \text { hepatic } \\
\text { steatosis, }{ }^{27} \text { and fibrosis }{ }^{28}\end{array}$ \\
\hline IL-6 & $\begin{array}{l}\text { Inflammation, }{ }^{29} \text { cell proliferation, } \\
\text { and carcinogenesis }{ }^{23}\end{array}$ \\
\hline \multicolumn{2}{|c|}{ M2 Kupffer cells } \\
\hline IL-4 & $\begin{array}{l}\text { Wound repair, }{ }^{30} \text { liver regeneration, }{ }^{31} \text { and } \\
\text { anti-inflammatory responses }\end{array}$ \\
\hline IL-10 & $\begin{array}{l}\text { Anti-inflammatory responses, }{ }^{33} \text { fibrosis, }^{34} \\
\text { bacteria clearance, }^{35} \text { apoptosis of M1 } \\
\text { macrophages }\end{array}$ \\
\hline IL-13 & Anti-inflammatory responses ${ }^{37}$ and fibrosis ${ }^{38}$ \\
\hline TGF- $\beta$ & Fibrosis $^{39}$ \\
\hline \multicolumn{2}{|l|}{ Others } \\
\hline IL-17 & Kupffer cell activation ${ }^{40}$ \\
\hline $\operatorname{miR}-124$ & Macrophage deactivation ${ }^{41}$ \\
\hline $\operatorname{miR}-155$ & Inhibition of M2 macrophage polarization ${ }^{42}$ \\
\hline $\operatorname{miR}-223$ & Inhibition of M1 macrophage polarization ${ }^{43}$ \\
\hline
\end{tabular}

TGF- $\beta$, transforming growth factor- $\beta$; TNF- $\alpha$, tumor necrosis factor- $\alpha$.

and regeneration during liver injury, although detailed functional differences between these two subsets of macrophages are still unclear and further studies are required.

\section{Functional Alterations of Kupffer Cells in Cholestatic Liver Disease}

Kupffer cells play an important role in liver pathology with various functions: i) engulf and eliminate foreign pathogens, apoptotic cells, and cell debris by phagocytosis; ii) present antigens to attract and stimulate $\mathrm{T}$ cells; iii) recruit nonparenchymal cells in the liver, including monocytes, neutrophils, natural killer $\mathrm{T}$ cells for immune responses; and iv) initiate an immune response in other liver cells, such as hepatocytes, by releasing active mediators, including cytokines, chemokines, and ROS. ${ }^{51}$ During cholestatic liver injury, however, various functional alterations of Kupffer cells and Kupffer cell-related physiological events that may be associated with disease conditions have been reported.

\section{Immunologic Abnormality}

One of the functions of Kupffer cells is to present antigens as previous studies have reported that human leukocyte antigen (HLA) genes are associated with cholestatic liver diseases. It has been reported that genome-wide association studies using primary biliary cirrhosis or primary sclerosing cholangitis patients identified candidate loci on regions of HLA. $^{52}$ A study using Japanese primary biliary cirrhosis patients has identified association between haplotypes of HLA class II and susceptibility and progression of primary

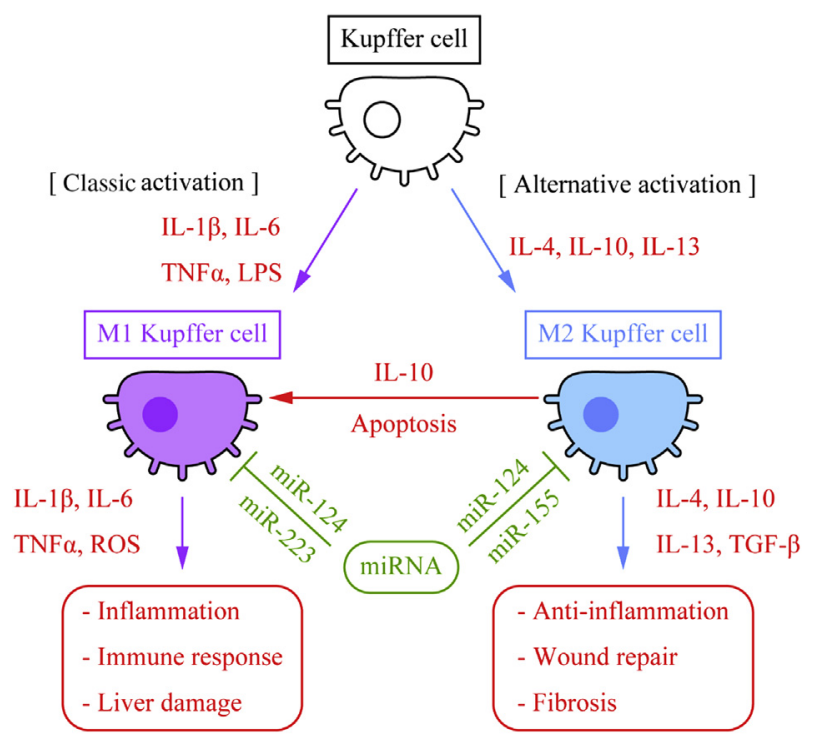

Figure $1 \quad M 1$ and M2 Kupffer cells. Kupffer cells are stimulated by various triggering agents and become active as M1 or M2 Kupffer cells. Foreign pathogens or proinflammatory cytokines activate Kupffer cells as M1 Kupffer cells, leading to further proinflammatory cytokine secretion or production of reactive oxygen species (ROS). 0ther cytokines, such as IL-4 and IL-13, promote Kupffer cell activation into M2 subsets, leading to antiinflammatory cytokine secretion, as well as transforming growth factor (TGF)- $\beta$ secretion, leading to fibrogenesis. A later study has shown that M2 Kupffer cells promote apoptosis of M1 Kupffer cells via IL-10 secretion to maintain homeostasis and balance of M1/M2 Kupffer cell population. ${ }^{36}$ Recent studies have demonstrated that some miRNAs can deactivate Kupffer cells or inhibit Kupffer cell activation, which may also be associated with liver diseases. ${ }^{41-43}$ LPS, lipopolysaccharide; TNF- $\alpha$, tumor necrosis factor- $\alpha$.

biliary cirrhosis. ${ }^{53}$ Intrahepatic cholestasis of pregnancy is a liver disorder specific to pregnancy characterized by increased levels of serum bile acids, although pathogenesis of intrahepatic cholestasis of pregnancy is still unknown. Yayi et $\mathrm{al}^{54}$ have revealed that cytokines for the M1 subset (TNF- $\alpha$ ) are increased and those for the M2 subset (IL-4) are decreased as well as HLA-G and HLA-E expressions are significantly decreased in intrahepatic cholestasis of pregnancy patients. Another study using human patients has also shown that down-regulation of HLA-G and up-regulation of miR-148a are associated with intrahepatic cholestasis of pregnancy. ${ }^{55}$ These studies suggest that HLA genes and antigen-presenting cells, including Kupffer cells, may be responsible for unbalanced cytokines and pathogenesis of cholestatic liver diseases.

\section{Impaired Bacterial Clearance}

A previous study using dogs has shown that BDL dogs fail rapid bacterial clearance from blood and bile after bacteria injection. ${ }^{56}$ Abe et $\mathrm{al}^{35}$ have found that BDL mice showed delayed clearance of bacteria and higher levels of IL-10 after bacterial injection compared with the sham-operated group. This study has also shown that in vivo administration of anti-IL-10 antibody improves bacterial clearance in BDL mice. Another study using IL-10 knockout mice, however, 
has demonstrated that IL-10 deficiency does not attenuate bacterial proliferation and even increases late mortality after BDL and Escherichia coli injection compared with wild type. ${ }^{57}$ Although IL-10 released from Kupffer cells may play an important role in bacterial clearance from the liver as well as anti-inflammatory response, only limited studies are available to date and detailed functions of IL-10 in cholestatic liver disease are still unknown.

\section{Cytokine Production}

Activated Kupffer cells secrete various mediators to recruit, activate, or initiate differentiation of other liver cells (Figure 2). BDL mice show elevated secretion of TNF- $\alpha$ and IL- 6 induced by LPS challenge. ${ }^{58}$ TNF- $\alpha$, IL- 1 , and IL-6 are major proinflammatory cytokines and are associated with cholestatic liver injury. A previous study has shown that TNF- $\alpha$ knockout mice show improved survival rate and attenuated BDL-induced liver damage and fibrosis. ${ }^{59}$ Another study using IL-1 receptor knockout mice has demonstrated that these mice show insusceptibility against LPS challenge after BDL, secreting fewer cytokines and showing lower mortality compared with wild-type mice. ${ }^{60}$ Deletion of IL- $1 \alpha$ also showed attenuated high-fat diet-induced inflammation as well as TNF- $\alpha$, IL-1 $\beta$, and IL-6 secretion. ${ }^{61}$ Deletion of IL-6, however, has shown significantly elevated cytokine secretion, including TNF- $\alpha$ and IL-1 $\beta$, as well as increased mortality against LPS challenge after BDL compared with wild-type mice. ${ }^{62}$ Another study has shown impaired immune responses of IL-6 knockout mice against LPS injection. ${ }^{63}$ These findings suggest that cytokines secreted from Kupffer cells are associated with liver conditions and mortality in cholestatic liver injury, although detailed mechanisms for each cytokine are unclear and functions may vary depending on cytokines.

\section{Activation of Kupffer Cells}

It is known that hypoxia-inducible factors are critical regulators of mediator production, such as monocyte chemotactic protein-1 by hypoxic Kupffer cells. ${ }^{64}$ A study using mouse models has demonstrated that selective knockout of hypoxia-inducible factors in bone marrow-derived liver macrophages attenuates liver fibrosis induced by BDL. ${ }^{65}$ Another study has shown that hypoxia-inducible factor- $1 \alpha$ knockout in HSCs decreases proinflammatory cytokine secretion and M1 macrophage differentiation, leading to impaired necrotic cell clearance caused by carbon tetrachloride injection in mice. ${ }^{66}$

IL-17 is secreted from neutrophils and T helper 17 cells, and recent studies have revealed that Kupffer cells can be regulated by $\mathrm{IL}-17$, leading to cytokine secretion during cholestatic liver injury. A study using IL-17A knockout mice has shown that IL-17A deficiency attenuates BDL-induced liver damage and expression levels of TNF- $\alpha$ and transforming growth factor- $\beta .^{40}$ This study has also shown that Kupffer cells treated with IL-17A secrete significantly higher levels of TNF- $\alpha$ and transforming growth factor- $\beta$ induced by LPS. Another study has shown that neutralization of IL-17A by anti-IL-17A antibody attenuates BDL-induced fibrosis and proinflammatory cytokine expression, including TNF- $\alpha$ and IL-6. ${ }^{67}$ Furthermore, IL-17 has been shown to promote proinflammatory and fibrogenic cytokines from Kupffer cells and enhances production of collagen type I in HSCs, leading to liver damage and fibrosis. ${ }^{68}$

Small noncoding RNAs, miRNAs, have also been suggested as Kupffer cell mediators. Xiao et $\mathrm{al}^{69}$ have demonstrated that BDL rats show elevated IL-6 expression and decreased miR-124 expression in the liver, and miR124 inhibits IL-6-mediated cholangiocyte proliferation by suppressing the expression levels of IL-6 receptor. miR-124 is also known to promote deactivation of macrophages in

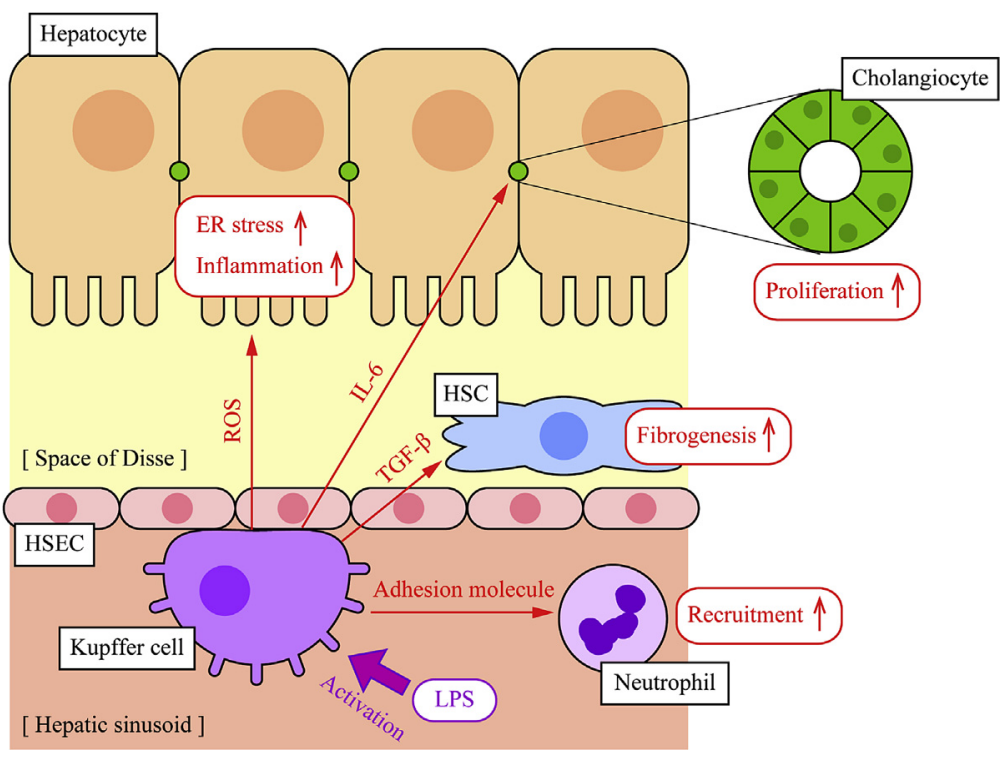

Figure 2 Functions of Kupffer cells in liver diseases. Kupffer cells are localized in hepatic sinusoid and can be mobile along with hepatic sinusoidal endothelial cells (HSECS) to encounter foreign materials effectively. Once Kupffer cells are activated, they secrete various mediators, including cytokines and chemokines, to stimulate other liver cells and initiate inflammatory responses. Cytokines, such as IL- 6 , induce inflammation and proliferation of hepatocytes and cholangiocytes. Transforming growth factor (TGF)- $\beta$ activates hepatic stellate cells (HSCS), leading to fibrosis, and reactive oxygen species (ROS) cause accumulation of unfolded proteins in the endoplasmic reticulum of hepatocytes, leading to hepatic steatosis and inflammation. Kupffer cells also secrete adhesion molecules to enhance interaction with neutrophils, and neutrophil accumulation helps pathogen clearance from blood stream. LPS, lipopolysaccharide. 
the brain. ${ }^{41}$ miR-155 is another candidate miRNA that may be associated with Kupffer cell activation. A previous study has reported that miR-155 enhances immune responses against LPS, and miR-155 deficiency attenuates hepatic steatosis and fibrosis induced by methionine-cholinedeficient diet. ${ }^{70}$ Arranz et al $^{71}$ have demonstrated that reduced levels of miR-155 leads to M2 Kupffer cell polarization and attenuates cytokine expression induced by LPS. Another study has also shown that miR-155 regulates IL-13 receptor $\alpha 1$ and inhibits polarization of M2 Kupffer cells via IL-13. ${ }^{42}$ It has also been reported that polarization of M1 macrophages can be regulated by miR-223. A study using the miR-223 knockout mouse model has demonstrated that miR-223 suppresses M1 macrophage polarization, and miR-223 deficiency exacerbates inflammation induced by high-fat diet. ${ }^{43}$ Although detailed mechanisms are still unclear and further studies are required, these previous studies suggest that transcription factors, cytokines, and miRNAs can regulate Kupffer cells and they could be a target for novel treatments of chronic cholestatic liver diseases.

\section{Orchestration of Kupffer Cells with Other Liver Cells during Liver Injury}

As described above, hypoxia-inducible factors and IL-17 can regulate Kupffer cell activation, which indicates that other liver cells, such as HSCs and neutrophils, may be able to regulate Kupffer cells via secretion of those mediators, and Kupffer cells may orchestrate with other liver cells to maintain liver homeostasis during liver injury. In fact, a previous study has demonstrated that ROS and IL- 6 activate Kupffer cells and these activated Kupffer cells modulate fibrogenic responses in HSCs. ${ }^{72}$ A latest study has also shown that HSCs receive an inflammation signal from sinusoids and relay it to parenchyma during concanavalin $\mathrm{A}-$ induced hepatitis in mice. ${ }^{73}$ Another study has shown that HSC depletion attenuates liver damage and TNF- $\alpha$ production caused by ischemia/reperfusion or LPS. ${ }^{74}$ There is also an implication that $42 \%$ of HSCs are vicinal to Kupffer cells in the liver, and these two cells may interact or communicate with each other for responses against liver injury, although further studies are required for conclusion. ${ }^{75}$ These earlier findings suggest that Kupffer cells and HSCs may orchestrate in signaling and cytokine secretion during liver diseases.

Kupffer cells also orchestrate with neutrophils in liver injury. BDL-induced cholestatic liver injury is associated with larger populations of Kupffer cells and neutrophils, ${ }^{76}$ and neutrophils are essential for collagenase activity and liver repair in BDL rats. ${ }^{77}$ Kupffer cells produce adhesion molecules that induce neutrophil interactions, promote neutrophil attachment to Kupffer cells, and promote clearance of bacteria in the liver. ${ }^{78} \mathrm{~A}$ recent study has shown that Kupffer cells coordinate with hepatic sinusoidal endothelial cells for neutrophil adhesion and recruitment during LPSinduced liver injury, and activation of Toll-like receptor 4, which is a receptor for LPS, in hepatic sinusoidal endothelial cells is essential. ${ }^{79}$

In cholestatic liver injury, portal fibroblasts may also be important for fibrosis. ${ }^{80}$ HSCs and portal fibroblasts are the major cellular sources of collagens in carbon tetrachloride or BDL-induced fibrogenesis, respectively. ${ }^{81}$ Another study has revealed that $>70 \%$ of myofibroblasts are derived from portal fibroblasts in BDL-induced cholestatic liver injury. ${ }^{82}$ Although only limited studies are available to date and further investigations are required, not only Kupffer cells but also other liver cells are associated with liver homeostasis, and these cells cooperate for the responses to liver injury. This suggests that these liver cells can be targets for the development of novel treatments.

\section{Protection or Promotion by Kupffer Cells in Cholestatic Liver Injury}

As Kupffer cells play a key role in signaling of liver inflammation and fibrosis, a potential approach for treatments is to block or deplete Kupffer cells. The function of Kupffer cells in liver pathology, however, is still controversial because depletion of Kupffer cells attenuates hepatic inflammation and liver damage in previous studies, ${ }^{83-86}$ although some recent studies claim that Kupffer cell depletion exacerbates liver damage..$^{87,88}$

\section{Kupffer Cells Promote Liver Injury}

Gadolinium chloride $\left(\mathrm{GdCl}_{3}\right)$ is the most widely used agent for macrophage blocking in immunology research. Administration of $5 \mathrm{mg} / \mathrm{kg} \mathrm{GdCl} \mathrm{Cl}_{3}$ blocks phagocytosis of Kupffer cells, and it reduces lethality against LPS challenge in rats. ${ }^{89}$ It has also been reported that $10 \mathrm{mg} / \mathrm{kg} \mathrm{GdCl}{ }_{3}$ pretreatment inhibits Kupffer cell activity during BDL and LPS challenge, and as a result, suppresses TNF- $\alpha$ secretion in rats. ${ }^{83}$ Another study has shown that daily $20 \mathrm{mg} / \mathrm{kg} \mathrm{GdCl}_{3}$ administration after BDL operation for 28 days attenuates liver damage and fibrosis in rats. ${ }^{84}$ Jones et al ${ }^{85}$ administered $10 \mathrm{mg} / \mathrm{kg} \mathrm{GdCl}_{3}$ to BDL rats 6 days after the surgery for 24 hours and found that $\mathrm{GdCl}_{3}$-treated rats showed fewer Kupffer cells, less liver damage, and lower plasma TNF- $\alpha$ levels. A study using liposomal clodronate for Kupffer cell depletion has shown that Kupffer cell-depleted rats show reduced TNF- $\alpha$ and IL-1 $\beta$ production. ${ }^{86}$ These studies suggest that Kupffer cells are responsible for promotion of cholestatic liver injury and hence depletion of Kupffer cells can be a tool for treatments.

\section{Kupffer Cells Protect Liver Injury}

Although some studies have shown that Kupffer cell depletion attenuates cholestatic liver injury, a few studies 
have suggested opposite implications. For example, Gehring et $\mathrm{al}^{87}$ have treated mice with liposome-encapsulated dichloromethylene diphosphonate before BDL to deplete Kupffer cells, and found that Kupffer cell-depleted mice show significantly more severe liver damage compared with control mice. Another study using alendronate for Kupffer cell depletion has revealed that Kupffer cell-depleted mice show more severe liver damage and decreased hepatocyte regeneration but also reduced fibrosis after BDL. ${ }^{88}$ These studies indicate that Kupffer cells protect the liver and are required for cell survival and regeneration in cholestatic liver injury.

\section{Limitations and Controversies in Kupffer Cell Research}

There are two hypotheses for functions of Kupffer cells and immune responses in liver pathology (Figure 3): Kupffer cell-induced responses, such as inflammation and fibrosis, are responsible for liver diseases, and hence depletion of Kupffer cells, followed by reduced immune responses, is a potential cure leading to better cell survival and liver conditions. Several studies have reported that depletion or blocking of Kupffer cells has protective effects against liver diseases, and this is still a common approach to seek a therapeutic target in live pathology. Alternatively, Kupffer cell-induced responses are a counteraction against triggers, such as pathogens and accumulated bile acids, and these

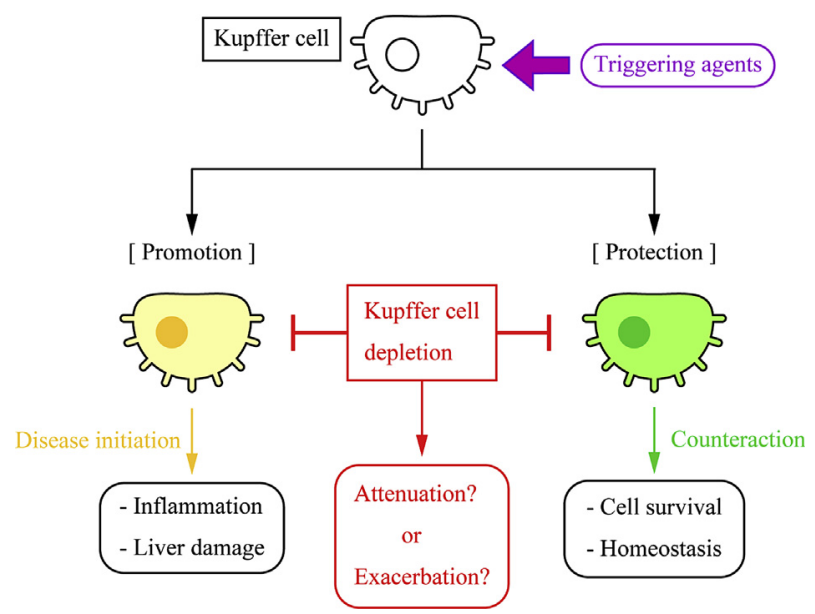

Figure 3 Promotion or protection of liver diseases by Kupffer cells. Various triggering agents, such as pathogens and lipopolysaccharide, activate Kupffer cells. Functions of activated Kupffer cells, however, are still controversial. Some previous studies have claimed that Kupffer cells initiate disease conditions, including inflammation and fibrosis, and hence Kupffer cell blocking or depletion can be a candidate approach for the treatment of liver diseases, which suggests that Kupffer cells are responsible for liver damage. ${ }^{83-86}$ In contrast, other studies have demonstrated that Kupffer cell depletion exacerbates liver damage, which implies that Kupffer cells protect the liver and activated Kupffer cells orchestrate with other cells for a counteraction against pathogens. ${ }^{87,88}$ This suggests that Kupffer cell-mediated responses are necessary for cell survival and Kupffer cell depletion cannot be a treatment of liver diseases. responses help cells to survive and maintain homeostasis, and hence depletion of Kupffer cells exacerbates liver diseases. These hypotheses are still controversial, and no conclusive studies have been established. There are some limitations and problems, however, in studies of Kupffer cells.

\section{Agents for Kupffer Cell Blocking or Depletion}

Previous studies use various agents for blocking or depletion of Kupffer cells, including $\mathrm{GdCl}_{3}$, liposomes containing clodronate, dichloromethylene diphosphonate, or alendronate. Selection of agents for Kupffer cell depletion may be critical, and different agents could produce different results. In addition, other factors induced by the agent itself should be considered. $\mathrm{GdCl}_{3}$, for example, is a blocker of L-type calcium channel located on the cell membrane and inhibits calcium influx into the cytosol through that channel. ${ }^{90}$ A previous study has shown that calcium signaling may play an important role in inflammatory responses and cytokine production, such as TNF$\alpha .{ }^{91}$ Calcium flash is also required for hydrogen peroxide production and wound inflammatory response. ${ }^{92}$ These studies suggest that Kupffer cell activation, followed by cytokine secretion and ROS production, may be an important signal to initiate inflammatory responses and could be regulated by free calcium in cytosol. It is also unknown if Kupffer cell blocking or depletion alters physiological events in the liver or other cells, such as bone marrow-derived macrophages can compensate functions of depleted Kupffer cells. Results may differ between short-time Kupffer cell blocking or depletion and long-term chronic treatment. Careful attention should be paid on agent selection and treatment procedures.

\section{Population of M1/M2 Kupffer Cells}

There are two subsets of Kupffer cells, M1 and M2, and their population may be critical for protection or promotion of cholestatic liver diseases. ${ }^{93}$ Populations or ratios of M1/ M2 Kupffer cells may change liver conditions or responses against triggering agents, although it is not easily feasible to discriminate and isolate M1 and M2 Kupffer cells. In addition, a study has shown that there are two subsets of M2 Kupffer cells showing different expression levels of marker proteins. ${ }^{94}$ It is known that Kupffer cells are positive for F4/80 and CD68, and M2 but not M1 Kupffer cells are positive for CD163, which is often used for discrimination between M1 and M2 Kupffer cells. Kinoshita et al, ${ }^{95}$ however, have demonstrated that within $\mathrm{F} 4 / 80^{+}$Kupffer cells, $46 \%$ are $\mathrm{CD}_{11 b^{-}} \mathrm{CD}^{+} 8^{+}, 22 \%$ are $\mathrm{CD} 11 \mathrm{~b}^{+} \mathrm{CD} 68^{-}$, and $6 \%$ are $\mathrm{CD} 11 \mathrm{~b}^{+} \mathrm{CD} 68^{+}$, and $\mathrm{CD} 68^{+}$subsets are functionally different from $\mathrm{CD} 11 \mathrm{~b}^{+}$subsets. Another study has shown that $\mathrm{CD}_{11} \mathrm{~b}^{+}$subsets may have higher secretion capacity of TNF- $\alpha$ compared with other subsets. ${ }^{96}$ Functional differences of Kupffer cell subsets are still largely 
unknown. In addition, it is also unknown which subsets can be blocked or depleted by the agents administered. Further studies are required to understand the association between M1/M2 Kupffer cells and liver conditions.

\section{Isolation of Kupffer Cells}

It is critical for Kupffer cell research to isolate primary Kupffer cells from liver specimens with good purity and cell viability. There are various isolation techniques available, although none of them are perfect and no golden standard method is established to date. Different isolation methods could produce different results because of varied cell viability or purity. Common methods include centrifugal elutriation and selective adherence. ${ }^{97,98}$ Density gradient centrifugation followed by magnetic-activated cell sorting gives high purity and cell viability, maintaining phagocytic activity of Kupffer cells after isolation, although it is still not feasible to eliminate contamination of other nonparenchymal cells. ${ }^{99}$ Lasercapture microdissection allows selective isolation of stained cells from tissues, and Gehring et al ${ }^{100}$ have demonstrated Kupffer cell isolation using laser capture microdissection and India ink injection for Kupffer cell staining. This technique can produce selective and high-quality RNA isolation of Kupffer cells from mouse liver sections, although this technique allows only RNA or DNA isolation and cell cultivation cannot be performed. Isolation of Kupffer cells is still challenging and, therefore, careful attention on experimental procedures and evidence for Kupffer cell viability and purity is required in Kupffer cell research.

\section{Conclusion}

Present studies have demonstrated that Kupffer cells are associated with cholestatic liver diseases, their functions are altered during liver injury and those physiological events are performed not only by Kupffer cells but also other liver cells communicating or regulating each other to orchestrate for liver homeostasis. There are controversial implications about Kupffer cell functions during liver injury, and further studies are required to confirm whether Kupffer cells are responsible for promotion or protection of liver damage and whether Kupffer cell depletion can be a treatment of liver diseases or exacerbate liver conditions. Although there are limitations in Kupffer cell research, it is important to understand functions and regulations of Kupffer cells and underlying mechanisms of liver damage with which Kupffer cells are associated to develop a novel treatment in cholestatic liver diseases.

\section{References}

1. Gao B, Jeong WI, Tian Z: Liver: an organ with predominant innate immunity. Hepatology 2008, 47:729-736

2. MacPhee PJ, Schmidt EE, Groom AC: Evidence for Kupffer cell migration along liver sinusoids, from high-resolution in vivo microscopy. Am J Physiol 1992, 263:G17-G23
3. Smedsrod B, De Bleser PJ, Braet F, Lovisetti P, Vanderkerken K, Wisse E, Geerts A: Cell biology of liver endothelial and Kupffer cells. Gut 1994, 35:1509-1516

4. Gossard AA, Talwalkar JA: Cholestatic liver disease. Med Clin North Am 2014, 98:73-85

5. Faubion WA, Guicciardi ME, Miyoshi H, Bronk SF, Roberts PJ, Svingen PA, Kaufmann SH, Gores GJ: Toxic bile salts induce rodent hepatocyte apoptosis via direct activation of Fas. J Clin Invest 1999, 103:137-145

6. Xia X, Francis H, Glaser S, Alpini G, LeSage G: Bile acid interactions with cholangiocytes. World J Gastroenterol 2006, 12 : $3553-3563$

7. Jones H, Alpini G, Francis H: Bile acid signaling and biliary functions. Acta Pharm Sin B 2015, 5:123-128

8. Alpini G, Glaser S, Alvaro D, Ueno Y, Marzioni M, Francis H, Baiocchi L, Stati T, Barbaro B, Phinizy JL, Mauldin J, LeSage G: Bile acid depletion and repletion regulate cholangiocyte growth and secretion by a phosphatidylinositol 3-kinase-dependent pathway in rats. Gastroenterology 2002, 123:1226-1237

9. Alpini G, Glaser S, Ueno Y, Rodgers R, Phinizy JL, Francis H, Baiocchi L, Holcomb LA, Caligiuri A, LeSage G: Bile acid feeding induces cholangiocyte proliferation and secretion: evidence for bile acid-regulated ductal secretion. Gastroenterology 1999, 116:179-186

10. Alpini G, Ueno Y, Glaser S, Marzioni M, Phinizy JL, Francis H, LeSage G: Bile acid feeding increased proliferative activity and apical bile acid transporter expression in both small and large rat cholangiocytes. Hepatology 2001, 34:868-876

11. Mancinelli R, Onori P, Gaudio E, Franchitto A, Carpino G, Ueno Y, Alvaro D, Annarale LP, DeMorrow S, Francis H: Taurocholate feeding to bile duct ligated rats prevents caffeic acid-induced bile duct damage by changes in cholangiocyte VEGF expression. Exp Biol Med 2009, 234:462-474

12. Haselow K, Bode JG, Wammers M, Ehlting C, Keitel V, Kleinebrecht L, Schupp AK, Haussinger D, Graf D: Bile acids PKAdependently induce a switch of the IL-10/IL-12 ratio and reduce proinflammatory capability of human macrophages. J Leukoc Biol 2013, 94:1253-1264

13. Calmus Y, Poupon R: Shaping macrophages function and innate immunity by bile acids: mechanisms and implication in cholestatic liver diseases. Clin Res Hepatol Gastroenterol 2014, 38:550-556

14. Correia L, Podevin P, Borderie D, Verthier N, Montet JC, Feldmann G, Poupon R, Weill B, Calmus Y: Effects of bile acids on the humoral immune response: a mechanistic approach. Life Sci 2001, 69:2337-2348

15. Scott-Conner CE, Grogan JB: The pathophysiology of biliary obstruction and its effect on phagocytic and immune function. J Surg Res 1994, 57:316-336

16. Minter RM, Fan MH, Sun J, Niederbichler A, Ipaktchi K, Arbabi S, Hemmila MR, Remick DG, Wang SC, Su GL: Altered Kupffer cell function in biliary obstruction. Surgery 2005, 138:236-245

17. Liedtke C, Luedde T, Sauerbruch T, Scholten D, Streetz K, Tacke F, Tolba R, Trautwein C, Trebicka J, Weiskirchen R: Experimental liver fibrosis research: update on animal models, legal issues and translational aspects. Fibrogenesis Tissue Repair 2013, 6:19

18. Chand N, Sanyal AJ: Sepsis-induced cholestasis. Hepatology 2007, $45: 230-241$

19. Nakano H, Fujiwara Y, Kitamura N, Kumada K, Matsumiya A, Sakai H, Hatakeyama T, Yamaguchi M, Jaeck D: Susceptibility to lipopolysaccharide of cholestatic rat liver produced with bile duct ligation: assessments of the mitochondrial glutathione pool and the effects of N-acetylcysteine. Eur Surg Res 2000, 32: $148-154$

20. O'Brien A, China L, Massey KA, Nicolaou A, Winstanley A, Newson J, Hobbs A, Audzevich T, Gilroy DW: Bile duct-ligated mice exhibit multiple phenotypic similarities to acute decompensation patients despite histological differences. Liver Int 2016, 36: 837-846 
21. Laskin DL, Sunil VR, Gardner CR, Laskin JD: Macrophages and tissue injury: agents of defense or destruction? Annu Rev Pharmacol Toxicol 2011, 51:267-288

22. Sica A, Mantovani A: Macrophage plasticity and polarization: in vivo veritas. J Clin Invest 2012, 122:787-795

23. Johnson C, Han Y, Hughart N, McCarra J, Alpini G, Meng F: Interleukin-6 and its receptor, key players in hepatobiliary inflammation and cancer. Transl Gastrointest Cancer 2012, 1:58-70

24. Merksamer PI, Papa FR: The UPR and cell fate at a glance. J Cell Sci 2010, 123:1003-1006

25. Schwabe RF, Brenner DA: Mechanisms of liver injury, I: TNF- $\alpha-$ induced liver injury: role of IKK, JNK, and ROS pathways. Am J Physiol Gastrointest Liver Physiol 2006, 290:G583-G589

26. Szabo G, Petrasek J: Inflammasome activation and function in liver disease. Nat Rev Gastroenterol Hepatol 2015, 12:387-400

27. Stienstra R, Saudale F, Duval C, Keshtkar S, Groener JE, van Rooijen N, Staels B, Kersten S, Muller M: Kupffer cells promote hepatic steatosis via interleukin-1 $\beta$-dependent suppression of peroxisome proliferator-activated receptor $\alpha$ activity. Hepatology 2010, 51: $511-522$

28. Gieling RG, Wallace K, Han YP: Interleukin-1 participates in the progression from liver injury to fibrosis. Am J Physiol Gastrointest Liver Physiol 2009, 296:G1324-G1331

29. Schmidt-Arras D, Rose-John S: IL-6 pathway in the liver: from physiopathology to therapy. J Hepatol 2016, 64:1403-1415

30. Salmon-Ehr V, Ramont L, Godeau G, Birembaut P, Guenounou M, Bernard P, Maquart FX: Implication of interleukin-4 in wound healing. Lab Invest 2000, 80:1337-1343

31. Goh YP, Henderson NC, Heredia JE, Red Eagle A, Odegaard JI, Lehwald N, Nguyen KD, Sheppard D, Mukundan L, Locksley RM, Chawla A: Eosinophils secrete IL-4 to facilitate liver regeneration. Proc Natl Acad Sci U S A 2013, 110:9914-9919

32. Kato A, Yoshidome H, Edwards MJ, Lentsch AB: Reduced hepatic ischemia/reperfusion injury by IL-4: potential anti-inflammatory role of STAT6. Inflamm Res 2000, 49:275-279

33. Gao B: Hepatoprotective and anti-inflammatory cytokines in alcoholic liver disease. J Gastroenterol Hepatol 2012, 27:89-93

34. Sziksz E, Pap D, Lippai R, Beres NJ, Fekete A, Szabo AJ, Vannay A: Fibrosis related inflammatory mediators: role of the IL-10 cytokine family. Mediators Inflamm 2015, 2015:764641

35. Abe T, Arai T, Ogawa A, Hiromatsu T, Masuda A, Matsuguchi T, Nimura Y, Yoshikai Y: Kupffer cell-derived interleukin 10 is responsible for impaired bacterial clearance in bile duct-ligated mice. Hepatology 2004, 40:414-423

36. Wan J, Benkdane M, Teixeira-Clerc F, Bonnafous S, Louvet A, Lafdil F, Pecker F, Tran A, Gual P, Mallat A, Lotersztajn S, Pavoine C: M2 Kupffer cells promote M1 Kupffer cell apoptosis: a protective mechanism against alcoholic and nonalcoholic fatty liver disease. Hepatology 2014, 59:130-142

37. Yoshidome H, Kato A, Miyazaki M, Edwards MJ, Lentsch AB: IL-13 activates STAT6 and inhibits liver injury induced by ischemia/reperfusion. Am J Pathol 1999, 155:1059-1064

38. Chiaramonte MG, Donaldson DD, Cheever AW, Wynn TA: An IL-13 inhibitor blocks the development of hepatic fibrosis during a T-helper type 2-dominated inflammatory response. J Clin Invest 1999, 104:777-785

39. Dooley $\mathrm{S}$, ten Dijke P: TGF- $\beta$ in progression of liver disease. Cell Tissue Res 2012, 347:245-256

40. Hara M, Kono H, Furuya S, Hirayama K, Tsuchiya M, Fujii H: Interleukin-17A plays a pivotal role in cholestatic liver fibrosis in mice. J Surg Res 2013, 183:574-582

41. Ponomarev ED, Veremeyko T, Barteneva N, Krichevsky AM, Weiner HL: MicroRNA-124 promotes microglia quiescence and suppresses EAE by deactivating macrophages via the C/EBP- $\alpha$-PU.1 pathway. Nat Med 2011, 17:64-70

42. Martinez-Nunez RT, Louafi F, Sanchez-Elsner T: The interleukin 13 (IL-13) pathway in human macrophages is modulated by microRNA-
155 via direct targeting of interleukin 13 receptor $\alpha 1$ (IL13R $\alpha 1$ ). J Biol Chem 2011, 286:1786-1794

43. Zhuang G, Meng C, Guo X, Cheruku PS, Shi L, Xu H, Li H, Wang G, Evans AR, Safe S, Wu C, Zhou B: A novel regulator of macrophage activation: miR-223 in obesity-associated adipose tissue inflammation. Circulation 2012, 125:2892-2903

44. Yona S, Kim KW, Wolf Y, Mildner A, Varol D, Breker M, StraussAyali D, Viukov S, Guilliams M, Misharin A, Hume DA, Perlman H, Malissen B, Zelzer E, Jung S: Fate mapping reveals origins and dynamics of monocytes and tissue macrophages under homeostasis. Immunity 2013, 38:79-91

45. Zigmond E, Samia-Grinberg S, Pasmanik-Chor M, Brazowski E, Shibolet O, Halpern Z, Varol C: Infiltrating monocyte-derived macrophages and resident kupffer cells display different ontogeny and functions in acute liver injury. J Immunol 2014, 193:344-353

46. Scott CL, Zheng F, De Baetselier P, Martens L, Saeys Y, De Prijck S, Lippens S, Abels C, Schoonooghe S, Raes G, Devoogdt N, Lambrecht BN, Beschin A, Guilliams M: Bone marrow-derived monocytes give rise to self-renewing and fully differentiated Kupffer cells. Nat Commun 2016, 7:10321

47. Ying W, Cheruku PS, Bazer FW, Safe SH, Zhou B: Investigation of macrophage polarization using bone marrow derived macrophages. J Vis Exp 2013, 76:e50323

48. Nishiyama K, Nakashima H, Ikarashi M, Kinoshita M, Nakashima M, Aosasa S, Seki S, Yamamoto J: Mouse CD11b ${ }^{+}$Kupffer cells recruited from bone marrow accelerate liver regeneration after partial hepatectomy. PLoS One 2015, 10:e136774

49. Elsegood CL, Chan CW, Degli-Esposti MA, Wikstrom ME, Domenichini A, Lazarus K, van Rooijen N, Ganss R, Olynyk JK, Yeoh GC: Kupffer cell-monocyte communication is essential for initiating murine liver progenitor cell-mediated liver regeneration. Hepatology 2015, 62:1272-1284

50. Yang L, Han Z, Tian L, Mai P, Zhang Y, Wang L, Li L: Sphingosine 1-phosphate receptor 2 and 3 mediate bone marrow-derived monocyte/macrophage motility in cholestatic liver injury in mice. Sci Rep 2015, 5:13423

51. Dixon LJ, Barnes M, Tang H, Pritchard MT, Nagy LE: Kupffer cells in the liver. Compr Physiol 2013, 3:785-797

52. Trivedi PJ, Hirschfield GM: The immunogenetics of autoimmune cholestasis. Clin Liver Dis 2016, 20:15-31

53. Umemura $\mathrm{T}$, Joshita $\mathrm{S}$, Ichijo $\mathrm{T}$, Yoshizawa $\mathrm{K}$, Katsuyama $\mathrm{Y}$, Tanaka E, Ota M: Human leukocyte antigen class II molecules confer both susceptibility and progression in Japanese patients with primary biliary cirrhosis. Hepatology 2012, 55:506-511

54. Yayi H, Danqing W, Shuyun L, Jicheng L: Immunologic abnormality of intrahepatic cholestasis of pregnancy. Am J Reprod Immunol 2010, 63:267-273

55. Zhang X, Yu L, Ding Y: Human leukocyte antigen G and miR-148a are associated with the pathogenesis of intrahepatic cholestasis of pregnancy. Exp Ther Med 2014, 8:1701-1706

56. Cardoso V, Pimenta A, da Fonseca JC, Rodrigues JS, Vaz MJ: The effect of cholestasis on hepatic clearance of bacteria. World J Surg 1982, 6:330-334

57. Jeyarajah DR, Kielar ML, Saboorian H, Karimi P, Frantz N, Lu CY: Impact of bile duct obstruction on hepatic E. coli infection: role of IL-10. Am J Physiol Gastrointest Liver Physiol 2006, 291:G91-G94

58. Lechner AJ, Velasquez A, Knudsen KR, Johanns CA, Tracy TF Jr, Matuschak GM: Cholestatic liver injury increases circulating TNF- $\alpha$ and IL-6 and mortality after Escherichia coli endotoxemia. Am J Respir Crit Care Med 1998, 157:1550-1558

59. Gabele E, Froh M, Arteel GE, Uesugi T, Hellerbrand C, Scholmerich J, Brenner DA, Thurman RG, Rippe RA: TNF $\alpha$ is required for cholestasis-induced liver fibrosis in the mouse. Biochem Biophys Res Commun 2009, 378:348-353

60. Sewnath ME, Van Der Poll T, Ten Kate FJ, Van Noorden CJ, Gouma DJ: Interleukin-1 receptor type I gene-deficient bile duct- 
ligated mice are partially protected against endotoxin. Hepatology 2002, 35:149-158

61. Olteanu S, Kandel-Kfir M, Shaish A, Almog T, Shemesh S, Barshack I, Apte RN, Harats D, Kamari Y: Lack of interleukin- $1 \alpha$ in Kupffer cells attenuates liver inflammation and expression of inflammatory cytokines in hypercholesterolaemic mice. Dig Liver Dis 2014, 46:433-439

62. Sewnath ME, van der Poll T, van Noorden CJ, ten Kate FJ, Gouma DJ: Cholestatic interleukin-6-deficient mice succumb to endotoxin-induced liver injury and pulmonary inflammation. Am J Respir Crit Care Med 2004, 169:413-420

63. Kopf M, Baumann H, Freer G, Freudenberg M, Lamers M, Kishimoto T, Zinkernagel R, Bluethmann H, Kohler G: Impaired immune and acute-phase responses in interleukin-6-deficient mice. Nature 1994, 368:339-342

64. Copple BL, Bai S, Moon JO: Hypoxia-inducible factor-dependent production of profibrotic mediators by hypoxic Kupffer cells. Hepatol Res 2010, 40:530-539

65. Copple BL, Kaska S, Wentling C: Hypoxia-inducible factor activation in myeloid cells contributes to the development of liver fibrosis in cholestatic mice. J Pharmacol Exp Ther 2012, 341:307-316

66. Mochizuki A, Pace A, Rockwell CE, Roth KJ, Chow A, O'Brien KM, Albee R, Kelly K, Towery K, Luyendyk JP, Copple BL: Hepatic stellate cells orchestrate clearance of necrotic cells in a hypoxia-inducible factor-1alpha-dependent manner by modulating macrophage phenotype in mice. J Immunol 2014, 192: $3847-3857$

67. Zhang S, Huang D, Weng J, Huang Y, Liu S, Zhang Q, Li N, Wen M, Zhu G, Lin F, Gu W: Neutralization of interleukin-17 attenuates cholestatic liver fibrosis in mice. Scand J Immunol 2016, 83: $102-108$

68. Meng F, Wang K, Aoyama T, Grivennikov SI, Paik Y, Scholten D, Cong M, Iwaisako K, Liu X, Zhang M, Osterreicher CH, Stickel F, Ley K, Brenner DA, Kisseleva T: Interleukin-17 signaling in inflammatory, Kupffer cells, and hepatic stellate cells exacerbates liver fibrosis in mice. Gastroenterology 2012, 143:765-776

69. Xiao Y, Wang J, Yan W, Zhou Y, Chen Y, Zhou K, Wen J, Wang Y, Cai W: Dysregulated miR-124 and miR-200 expression contribute to cholangiocyte proliferation in the cholestatic liver by targeting IL6/STAT3 signalling. J Hepatol 2015, 62:889-896

70. Csak T, Bala S, Lippai D, Kodys K, Catalano D, Iracheta-Vellve A, Szabo G: MicroRNA-155 deficiency attenuates liver steatosis and fibrosis without reducing inflammation in a mouse model of steatohepatitis. PLoS One 2015, 10:e0129251

71. Arranz A, Doxaki C, Vergadi E, Martinez de la Torre Y, Vaporidi K, Lagoudaki ED, Ieronymaki E, Androulidaki A, Venihaki M, Margioris AN, Stathopoulos EN, Tsichlis PN, Tsatsanis C: Akt1 and Akt2 protein kinases differentially contribute to macrophage polarization. Proc Natl Acad Sci U S A 2012, 109:9517-9522

72. Nieto N: Oxidative-stress and IL-6 mediate the fibrogenic effects of rodent Kupffer cells on stellate cells. Hepatology 2006, 44: $1487-1501$

73. Fujita T, Soontrapa K, Ito Y, Iwaisako K, Moniaga CS, Asagiri M, Majima M, Narumiya S: Hepatic stellate cells relay inflammation signaling from sinusoids to parenchyma in mouse models of immunemediated hepatitis. Hepatology 2016, 63:1325-1339

74. Stewart RK, Dangi A, Huang C, Murase N, Kimura S, Stolz DB, Wilson GC, Lentsch AB, Gandhi CR: A novel mouse model of depletion of stellate cells clarifies their role in ischemia/reperfusionand endotoxin-induced acute liver injury. J Hepatol 2014, 60: 298-305

75. Marcos R: Depletion of hepatic stellate cells: have Kupffer cells lost their bad neighbor? J Hepatol 2014, 61:714-715

76. Harty MW, Huddleston HM, Papa EF, Puthawala T, Tracy AP, Ramm GA, Gehring S, Gregory SH, Tracy TF Jr: Repair after cholestatic liver injury correlates with neutrophil infiltration and matrix metalloproteinase 8 activity. Surgery 2005, 138:313-320
77. Harty MW, Muratore CS, Papa EF, Gart MS, Ramm GA, Gregory SH, Tracy TF Jr: Neutrophil depletion blocks early collagen degradation in repairing cholestatic rat livers. Am J Pathol 2010, 176: $1271-1281$

78. Gregory SH, Cousens LP, van Rooijen N, Dopp EA, Carlos TM, Wing EJ: Complementary adhesion molecules promote neutrophilKupffer cell interaction and the elimination of bacteria taken up by the liver. J Immunol 2002, 168:308-315

79. McDonald B, Jenne CN, Zhuo L, Kimata K, Kubes P: Kupffer cells and activation of endothelial TLR4 coordinate neutrophil adhesion within liver sinusoids during endotoxemia. Am J Physiol Gastrointest Liver Physiol 2013, 305:G797-G806

80. Dranoff JA, Wells RG: Portal fibroblasts: underappreciated mediators of biliary fibrosis. Hepatology 2010, 51:1438-1444

81. Perepelyuk M, Terajima M, Wang AY, Georges PC, Janmey PA, Yamauchi M, Wells RG: Hepatic stellate cells and portal fibroblasts are the major cellular sources of collagens and lysyl oxidases in normal liver and early after injury. Am J Physiol Gastrointest Liver Physiol 2013, 304:G605-G614

82. Iwaisako K, Jiang C, Zhang M, Cong M, Moore-Morris TJ, Park TJ, Liu X, Xu J, Wang P, Paik YH, Meng F, Asagiri M, Murray LA, Hofmann AF, Iida T, Glass CK, Brenner DA, Kisseleva T: Origin of myofibroblasts in the fibrotic liver in mice. Proc Natl Acad Sci U S A 2014, 111:E3297-E3305

83. Abraham S, Szabo A, Kaszaki J, Varga R, Eder K, Duda E, Lazar G, Tiszlavicz L, Boros M, Lazar G Jr: Kupffer cell blockade improves the endotoxin-induced microcirculatory inflammatory response in obstructive jaundice. Shock 2008, 30:69-74

84. Zandieh A, Payabvash S, Pasalar P, Morteza A, Zandieh B, Tavangar SM, Dehpour AR: Gadolinium chloride, a Kupffer cell inhibitor, attenuates hepatic injury in a rat model of chronic cholestasis. Hum Exp Toxicol 2011, 30:1804-1810

85. Jones C, Badger SA, Hoper M, Parks RW, Diamond T, Taylor MA: Hepatic cytokine response can be modulated using the Kupffer cell blocker gadolinium chloride in obstructive jaundice. Int J Surg 2013, 11:46-51

86. Sturm E, Havinga R, Baller JF, Wolters $H$, van Rooijen $N$, Kamps JA, Verkade HJ, Karpen SJ, Kuipers F: Kupffer cell depletion with liposomal clodronate prevents suppression of Ntcp expression in endotoxin-treated rats. J Hepatol 2005, 42:102-109

87. Gehring S, Dickson EM, San Martin ME, van Rooijen N, Papa EF, Harty MW, Tracy TF Jr, Gregory SH: Kupffer cells abrogate cholestatic liver injury in mice. Gastroenterology 2006, 130:810-822

88. Osawa Y, Seki E, Adachi M, Suetsugu A, Ito H, Moriwaki H, Seishima M, Nagaki M: Role of acid sphingomyelinase of Kupffer cells in cholestatic liver injury in mice. Hepatology 2010, 51: 237-245

89. Iimuro Y, Yamamoto M, Kohno H, Itakura J, Fujii H, Matsumoto Y: Blockade of liver macrophages by gadolinium chloride reduces lethality in endotoxemic rats: analysis of mechanisms of lethality in endotoxemia. J Leukoc Biol 1994, 55:723-728

90. Roland CR, Naziruddin B, Mohanakumar T, Flye MW: Gadolinium blocks rat Kupffer cell calcium channels: relevance to calciumdependent prostaglandin E2 synthesis and septic mortality. Hepatology 1999, 29:756-765

91. Brown DM, Donaldson K, Stone V: Role of calcium in the induction of TNF $\alpha$ expression by macrophages on exposure to ultrafine particles. Ann Occup Hyg 2002, 46:219-222

92. Razzell W, Evans IR, Martin P, Wood W: Calcium flashes orchestrate the wound inflammatory response through DUOX activation and hydrogen peroxide release. Curr Biol 2013, 23:424-429

93. Tacke F, Zimmermann HW: Macrophage heterogeneity in liver injury and fibrosis. J Hepatol 2014, 60:1090-1096

94. He Y, Sadahiro T, Noh SI, Wang H, Todo T, Chai NN, Klein AS, Wu GD: Flow cytometric isolation and phenotypic characterization of two subsets of ED2 ${ }^{+}$(CD163) hepatic macrophages in rats. Hepatol Res 2009, 39:1208-1218 
95. Kinoshita M, Uchida T, Sato A, Nakashima M, Nakashima H, Shono S, Habu Y, Miyazaki H, Hiroi S, Seki S: Characterization of two F4/80-positive Kupffer cell subsets by their function and phenotype in mice. J Hepatol 2010, 53:903-910

96. Nakashima H, Ogawa Y, Shono S, Kinoshita M, Nakashima M, Sato A, Ikarashi M, Seki S: Activation of $\mathrm{CD}_{11 \mathrm{~b}^{+}}$Kupffer cells/macrophages as a common cause for exacerbation of TNF/Fas-liganddependent hepatitis in hypercholesterolemic mice. PLoS One 2013, 8: e49339

97. Janousek J, Strmen E, Gervais F: Purification of murine Kupffer cells by centrifugal elutriation. J Immunol Methods 1993, 164:109-117
98. Alabraba EB, Curbishley SM, Lai WK, Wigmore SJ, Adams DH, Afford SC: A new approach to isolation and culture of human Kupffer cells. J Immunol Methods 2007, 326:139-144

99. Werner M, Driftmann S, Kleinehr K, Kaiser GM, Mathe Z, Treckmann JW, Paul A, Skibbe K, Timm J, Canbay A, Gerken G, Schlaak JF, Broering R: All-in-one: advanced preparation of human parenchymal and non-parenchymal liver cells. PLoS One 2015, 10: e0138655

100. Gehring S, Sabo E, San Martin ME, Dickson EM, Cheng CW, Gregory SH: Laser capture microdissection and genetic analysis of carbon-labeled Kupffer cells. World J Gastroenterol 2009, 15:1708-1718 